\title{
Changes in lipid, lipoprotein and apolipoprotein profiles in persons with spinal cord injuries during the first 2 years post-injury
}

\author{
AJ Dallmeijer*,1 LHV van der Woude $^{1}$, GJ van Kamp ${ }^{2}$ and AP Hollander ${ }^{1}$ \\ ${ }^{1}$ Institute for Fundamental and Clinical Human Movement Sciences, Faculty of Human Movement Sciences, \\ Vrije Universiteit Amsterdam, The Netherlands and ${ }^{2}$ Department of Clinical Chemistry, Vrije Universiteit Amsterdam, \\ The Netherlands
}

\begin{abstract}
Objective: To investigate changes in lipid, lipoprotein and apolipoprotein profiles in persons with spinal cord injury (SCI) during the first 2 years post-injury, and to determine whether changes in risk profiles were associated with sport activity and/or changes in physical capacity parameters.

Design: Risk profiles and physical capacity were investigated in 19 subjects with recent SCI during rehabilitation ( $\mathrm{t} 1)$ and \pm 1 year after discharge from rehabilitation $(\mathrm{t} 2)$.

Main outcome measures: Changes in total plasma cholesterol (TC), high-density lipoprotein cholesterol (HDL-C), low-density lipoprotein cholesterol (LDL-C), triglycerides (TG), apolipoprotein-A1 (ApoA1), apolipoprotein-B (ApoB) concentrations, the ratios TC/HDLC, LDL-C/HDL-C, ApoA1/ApoB and HDL-C/ApoA1, and physical capacity (maximal isometric strength, sprint power output, maximal power output, aerobic power).

Results: Risk profile parameters changed towards more favorable values at $\mathrm{t} 2$, except for HDL-C $(P=0.06)$, TG and HDL-C/ApoA1. Sport activity and changes of the physical capacity were the most important determinants of changes in lipid and (apo)lipoprotein profiles, showing more favorable values with larger increases of the physical capacity and in persons who were physically active.

Conclusion: Results show that the lipid and (apo)lipoprotein profiles improve in persons with SCI during the first 2 years post-injury, and that improving the physical capacity or being physically active can improve the lipid and (apo)lipoprotein profiles.
\end{abstract}

Keywords: coronary heart disease; paraplegia; physical capacity; rehabilitation; sport activity; tetraplegia

\section{Introduction}

In recent years, a number of studies showed that persons with spinal cord injuries (SCI) are at increased risk of coronary heart diseases (CHD) in comparison with the able bodied population. ${ }^{1-3}$ Apart from epidemiological evidence, it was found that the lipid and (apo)lipoprotein profiles of persons with SCI differed from those common in the able bodied population, showing unfavorable profiles in persons with SCI. ${ }^{4-9}$ Despite normal levels of total cholesterol, depressed values of high-density lipoprotein cholesterol (HDL-C) have been reported in comparison with able bodied subjects. ${ }^{4-8}$ In addition, it was found that apolipoprotein-A1 levels were depressed and apolipoprotein-B concentrations were increased in persons with SCI, ${ }^{9,10}$ also indicating an increased risk of CHD. The importance of apolipoproteins in assessing the risk of CHD has recently been underlined. ${ }^{11,12}$

*Correspondence: AJ Dallmeijer, Faculty of Human Movement Sciences, Vrije Universiteit Amsterdam, Van der Boechorststraat 9, 1081 BT Amsterdam, The Netherlands
Many authors suggested that the low HDL-C concentrations, and concomitant depressed levels of apolipoprotein-A1, in persons with SCI are the consequence of extremely low levels of physical activity, mainly resulting from their wheelchair dependent life. ${ }^{4,5,7,9}$ Previous studies indeed showed that physical strain in daily life of persons with SCI was too low to maintain or improve physical fitness. ${ }^{13,14}$ The effect of physical activity on the lipid and (apo)lipoprotein profiles in persons with SCI has, until now, only been investigated in a cross-sectional set-up. ${ }^{4,5,9,10,15}$ More favorable risk profiles were reported in wheelchair athletes, ${ }^{4,5}$ and moderately active subjects with tetraplegia, ${ }^{9}$ in comparison with their sedentary counterparts. Janssen et $a l^{10}$ found a positive relationship between hours sport participation per week and more favorable values of risk profile parameters. In addition, Bostom et al ${ }^{15}$ showed that aerobic power was associated with more favorable lipid and (apo)lipoprotein concentrations in welltrained subjects with paraplegia. The only longitudinal training study in persons with SCI, investigat- 
ing the effects of training, also showed improvements in risk profiles after training, but conclusions were limited as a consequence of the small sample sizes and differences in pre-training values between groups. ${ }^{16}$

Few studies investigated the lipoprotein profiles shortly after injury. ${ }^{4,17}$ In these studies extremely low HDL-C concentrations were found within a few months post-injury. Additionally, Brenes et $a l^{4}$ found a (cross-sectional) positive relationship between time since injury and HDL-C levels in persons with SCI, with a time since injury ranging from 6-52 weeks. These results suggest that the (unfavorable) risk profiles in recently injured persons improve during the first months post-injury, probably as a result of an increased activity level. During rehabilitation, the level of physical activity is assumed to be fairly high, and more or less the same in all individuals. After discharge from rehabilitation, however, it depends on several factors whether subjects will become more sedentary, or will continue to participate in sport activities. It is expected that individuals who become physically active after rehabilitation, will show larger improvements in risk profiles, than persons who adopt a sedentary life-style. In addition, improvements of the physical capacity are also expected to result in more favorable risk profiles.

The purpose of this study was (1) to investigate changes in the lipid, lipoprotein and apolipoprotein profiles in persons with SCI during the first 2 years post-injury, and (2) to determine whether changes in the risk profiles were associated with sport activity and/or changes in physical capacity parameters.

\section{Methods}

\section{Subjects and protocol}

To investigate changes in the lipid and (apo)lipoprotein profiles in relation to sport activity and changes in physical capacity, 26 subjects with SCI were investigated during their rehabilitation period ( $\mathrm{t} 1)$, and \pm 1 year after discharge from the rehabilitation center (t2). Written informed consent was obtained from all subjects. Measurements at tl were performed at different stages during the rehabilitation process. Consequently, a variable period of time between t1 and $\mathrm{t} 2$ was spent in the rehabilitation center. Mean time since injury at $t 1$ was $173 \pm 102$ days. Mean time between measurements was $587 \pm 139$ days. Time between discharge from rehabilitation and $\mathrm{t} 2$ was \pm 1 year for all subjects.

At t2, seven subjects dropped out for several reasons (moved too far away $[n=4]$, illnesses or pain $[n=2]$, and to busy with work $[n=1])$. The statistical analysis was performed with the remaining 19 subjects who completed the study. Of these subjects, nine persons had a tetraplegia (two females) and ten persons had a paraplegia (two females). All subjects were wheelchair dependent and were able to propel a hand rim wheelchair independently. Lesion level ranged from C6 to L3/4. Four subjects with tetraplegia and three subjects with paraplegia had incomplete lesions (modified ASIA impairment scale: B: $[n=2], C[n=3]$ and $\mathrm{D}[n=2])$. The number of subjects specified by lesion level and gender is given in Table 1.

Initially, all subjects were patients of the Rehabilitation Center Amsterdam (The Netherlands). Subjects with cardiovascular diseases were excluded from the study. Mean age at $t 1$ was $40.7 \pm 14.7$ years (range: 24-68 years). All subjects were participants of a longitudinal study on physical performance during rehabilitation in persons with SCI. ${ }^{18}$ Blood samples were taken in the morning, when most subjects were in fasting state. Some subjects had taken a low fat breakfast only (bread and tea), at least $2 \mathrm{~h}$ before blood samples were taken.

A questionnaire was used to assess alcohol consumption (number of glasses per week), smoking behavior (number of cigarettes per day) and history of CHD in parents, brothers and/or sisters. Sport activity, defined as hours of physical activity per week during the year preceding $\mathrm{t} 2$, was investigated at t2 only, because during the rehabilitation period physical activity was assumed to be comparable in all subjects. Individually initiated activities, like outdoor arm-crank training were also included as sport activity.

Body mass was measured on a hospital scale, and skinfolds were measured at biceps, triceps, subscapular and suprailiacal site, by the same test leader. Body mass index (BMI $\left[\mathrm{kg} \cdot \mathrm{m}^{-2}\right]$ ) was calculated as body mass divided by the square of self reported height. Subject characteristics at $\mathrm{t} 1$ and $\mathrm{t} 2$ are shown in Table 2.

\section{Blood lipids and (apo)lipoproteins}

Total cholesterol (TC) and triglyceride (TG) concentrations were measured using enzymatic, colorimetric tests on the Hitachi 747 automated analyzer (Boehringer Mannheim GmbH, Mannheim, Germany). HDL-C was determined after selective precipitation of the very low-density lipoprotein and lowdensity lipoprotein fractions; low-density lipoprotein cholesterol (LDL-C) was calculated using the Friedewald formula. Apolipoproteins-A1 (ApoA1) and -B (ApoB) were quantitated with an immunonephelometric method on the Beckman Array 360 system (Beckham Instruments Inc, Brea CA, USA). The ratios

Table 1 Number of subjects specified by lesion level and gender

\begin{tabular}{lccccc}
\hline & & C5-C8 & Th1-Th10 & Th11-L4 & Total \\
\hline Complete & \multirow{2}{*}{} & 4 & 1 & 5 & 10 \\
& + & 1 & 1 & 0 & 2 \\
Incomplete & 0 & 3 & 0 & 2 & 5 \\
\multirow{2}{*}{ Total } & + & 1 & 0 & 1 & 2 \\
\hline
\end{tabular}


TC/HDL-C, LDL-C/HDL-C, ApoA1/ApoB, and HDL-C/ApoA1 were calculated.

\section{Physical capacity}

To investigate whether changes of the physical capacity were related to changes in the lipid and (apo)lipoprotein profiles, results of separate exercise tests, measured on the same occasion and with the same subjects, ${ }^{18}$ were used to calculate percentage change $(\% \Delta)$ in maximal isometric strength (Fiso [N]), sprint power output (P30 [W]), maximal power output (POmax [W]) and peak oxygen uptake $\left(\mathrm{VO}_{2}\right.$ peak $\left.\left[1 . \min ^{-1}\right]\right)$.

\section{Statistics}

Paired Student $t$-tests were applied to detect significant differences between $\mathrm{t} 1$ and $\mathrm{t} 2$. Stepwise multiple regression analysis was used to investigate the determinants of the changes in the lipid and (apo)lipoprotein profiles, using as independent variables: age, gender $(\operatorname{men}=1$, women $=0)$, lesion level (paraplegia $=1$, tetraplegia $=0$ ), completeness of the lesion $($ complete $=1$, incomplete $=0$ ), changes in BMI and sum of four skinfolds, family history of CHD (with $\mathrm{CHD}$ history $=1$, no CHD history $=0$ ), smoking behavior at $\mathrm{t} 2$, alcohol consumption at $\mathrm{t} 2$, sport activity at $\mathrm{t} 2$ (group $1<1 \mathrm{~h}^{\mathrm{wh}}{ }^{-1}$, group 2 $\geqslant 1 \mathrm{~h} . \mathrm{wk}^{-1}$ and $<3 \mathrm{~h} . \mathrm{wk}^{-1}$, group $3 \geqslant 3 \mathrm{~h} . \mathrm{wk}^{-1}$ ), percentage change of physical capacity parameters $\left(\% \Delta\right.$ Fiso, $\% \Delta \mathrm{P} 30, \% \Delta \mathrm{PO} \max , \% \Delta \mathrm{VO}_{2}$ peak $)$, both expressed absolute and relative to body mass. The values of the lipid and (apo)lipoprotein parameters at t1 were also used as independent variables to investigate whether the initial levels were associated to changes in risk profile parameters. Results were considered significant at $P<0.05$.

\section{Results}

\section{Subjects}

Smoking behavior and alcohol consumption showed no changes over time. Eleven subjects were non-smoking at $\mathrm{t} 1$, and 12 subjects were non-smoking at t2. Eight subjects were inactive (eg physically active for less than $1 \mathrm{~h}$ per week), three subjects reported physical activities of at least $1 \mathrm{~h}$ per week, but less than $3 \mathrm{~h}$ per week, and eight subjects participated in sport activities for at least $3 \mathrm{~h}$ per week. Body mass and BMI increased significantly from $73 \pm 13 \mathrm{~kg}$ and $22 \pm 4 \mathrm{~kg} . \mathrm{m}^{-2}$ at t1, to $80 \pm 15 \mathrm{~kg}$ and $24 \pm 4 \mathrm{~kg} . \mathrm{m}^{-2}$ at t2, respectively. The sum of four skinfolds showed no significant change between $\mathrm{t} 1$ and $\mathrm{t} 2$ (Table 2).

\section{Physical capacity}

Results for the physical capacity at $\mathrm{t} 1$ and $\mathrm{t} 2$ are listed in Table 3. Physical capacity parameters are both

Table 2 Subject characteristics and behavioral factors $(n=19)$

\begin{tabular}{|c|c|c|c|c|}
\hline & $\begin{array}{c}t 1 \\
\text { mean } \pm S D\end{array}$ & $\begin{array}{c}t 2 \\
\text { mean } \pm S D\end{array}$ & $\begin{array}{c}\Delta \\
m e a n \pm S D\end{array}$ & $\mathrm{P}$-value \\
\hline Age (years) & $40.7 \pm 14.7$ & - & - & - \\
\hline Time since injury (days) & $173 \pm 102$ & $760 \pm 169$ & $587 \pm 139$ & - \\
\hline Body mass $(\mathrm{kg})$ & $72.9 \pm 12.5$ & $79.7 \pm 15.3$ & $6.8 \pm 6.4$ & 0.000 \\
\hline BMI (kg.m $\left.{ }^{-2}\right)$ & $22.1 \pm 3.5$ & $24.1 \pm 4.2$ & $2.0 \pm 2.0$ & 0.000 \\
\hline Skinfolds (mm) & $39.4 \pm 13.5$ & $42.3 \pm 16.0$ & $2.9 \pm 10.5$ & 0.170 \\
\hline Smoking (cigarettes per day) & $4.8 \pm 8.1$ & $5.7 \pm 8.9$ & $0.8 \pm 3.3$ & 0.279 \\
\hline Alcohol consumption (glasses per week) & $6.9 \pm 9.6$ & $7.7 \pm 9.9$ & $0.8 \pm 9.2$ & 0.713 \\
\hline Sport (h.week ${ }^{-1}$ ) & - & $2.6 \pm 3.0$ & - & - \\
\hline
\end{tabular}

t1: during rehabilitation; $\mathrm{t} 2: \pm 1$ year after discharge from rehabilitation; $\Delta:$ value at $\mathrm{t} 2$ minus value at $\mathrm{t} 1$

Table 3 Physical capacity parameters at t1 and t2 $(n=19)$

\begin{tabular}{|c|c|c|c|c|}
\hline & $\begin{array}{c}t 1 \\
\text { mean } \pm S D\end{array}$ & $\begin{array}{c}t 2 \\
\text { mean } \pm S D\end{array}$ & $\begin{array}{c}\% \Delta \\
m e a n \pm S D\end{array}$ & $\mathrm{P}$-value \\
\hline Fiso $(\mathrm{N})$ & $204 \pm 109$ & $227 \pm 112$ & $26.8 \pm 50.6$ & 0.091 \\
\hline Fiso $\left(\mathrm{N} . \mathrm{kg}^{-1}\right)$ & $2.8 \pm 1.4$ & $2.8 \pm 1.2$ & $15.7 \pm 42.5$ & 0.770 \\
\hline P30 (W) & $63.2 \pm 41.2$ & $76.7 \pm 50.5$ & $28.9 \pm 36.0$ & 0.001 \\
\hline $\mathrm{P} 30\left(\mathrm{~W} \cdot \mathrm{kg}^{-1}\right)$ & $0.87 \pm 0.57$ & $0.97 \pm 0.63$ & $17.9 \pm 30.7$ & 0.010 \\
\hline POmax (W) & $34.6 \pm 25.1$ & $44.7 \pm 30.9$ & $46.7 \pm 57.9$ & 0.001 \\
\hline POmax $\left(\mathrm{W} . \mathrm{kg}^{-1}\right)$ & $0.47 \pm 0.34$ & $0.56 \pm 0.39$ & $33.4 \pm 47.3$ & 0.006 \\
\hline $\mathrm{VO}_{2}$ peak $\left(1 . \mathrm{min}^{-1}\right)$ & $1.01 \pm 0.48$ & $1.09 \pm 0.59$ & $6.0 \pm 21.0$ & 0.110 \\
\hline $\mathrm{VO}_{2}$ peak $\left(\mathrm{ml} \cdot \mathrm{min}^{-1} \cdot \mathrm{kg}^{-1}\right)$ & $13.9 \pm 6.9$ & $13.7 \pm 7.7$ & $-3.1 \pm 16.9$ & 0.623 \\
\hline
\end{tabular}

t1: during rehabilitation; $\mathrm{t} 2$ : \pm 1 year after discharge from rehabilitation; $\% \Delta$ : percentage change 
expressed as absolute values as well as relative to body mass. P30 and POmax increased significantly at t2, both for absolute values and values relative to body mass. For Fiso and $\mathrm{VO}_{2}$ peak no significant changes were found between $\mathrm{t} 1$ and $\mathrm{t} 2$.

\section{Changes in lipid and (apo)lipoprotein profiles}

Results of the blood analyses are listed in Table 4. Most parameters showed significant improvement (eg more healthy values) at $\mathrm{t} 2$. Significantly lower values were found at $\mathrm{t} 2$ for TC, LDL-C, and the ratios TC/ HDL-C and LDL-C/HDL-C. HDL-C showed no significant differences between $\mathrm{t} 1 \quad(0.93+$ $\left.0.20 \mathrm{mmol}^{-1}\right)$ and $\mathrm{t} 2 \quad\left(1.02 \pm 0.26 \mathrm{mmol}^{-1} \mathrm{1}^{-1}\right)$ although a tendency for higher values at $\mathrm{t} 2$ could be observed $(P=0.06)$. TG values were not significantly different between $t 1$ and $t 2$. ApoA1 increased significantly from $1.12 \pm 0.14 \mathrm{~g} .1^{-1}$ at $\mathrm{t} 1$, to $1.20 \pm 0.21$ g. $1^{-1}$ at $\mathrm{t} 2$, and ApoB decreased significantly from $1.11 \pm 0.28 \mathrm{~g} .1^{-1}$ at $\mathrm{t} 1$, to $1.05 \pm 0.29 \mathrm{~g} .1^{-1}$ at $t 2$. Consequently, the ratio $A p o A 1 / A p o B$ was significantly higher at $\mathrm{t} 2(1.22 \pm 0.33)$ than at $\mathrm{t} 1$ $(1.07 \pm 0.32)$. The ratio $\mathrm{HDL}-\mathrm{C} / \mathrm{A}$ poA 1 showed no significant differences between the two measurements.

\section{Determinants of changes in the lipid and (apo) lipoprotein profiles}

Results of the regression analyses are shown in Table 5. Regression analyses showed that sport activity at $\mathrm{t} 2$, changes in physical capacity parameters, and initial values of the risk profile parameters (at t1) were the most important determinants of changes in the lipid and (apo)lipoprotein profiles. Sport activity was the most important determinant of changes in TC, LDL-C and TC/HDL-C, explaining 34, 47 and $29 \%$ of the variance, respectively. These findings imply that subjects who were physically active showed larger improvements of the risk profiles than sedentary or less active subjects. In addition, improvements of the physical capacity were associated with more favorable values of the risk profiles; changes in Fiso, P30,
POmax and $\mathrm{VO}_{2}$ peak showed a negative relationship with changes in LDL-C/HDL-C, TG, and ApoB, and were positively associated with changes of TC, HDL-C, and ApoA1/ApoB.

Initial values of LDL-C, TC/HDL-C, and LDL-C/ HDL-C were significant determinants of changes in these parameters, showing that subjects with initially less favorable risk profiles showed larger improvements. Changes in the sum of four skinfolds was the most important factor explaining changes of $\mathrm{TG}$; increases in the sum of four skinfolds were associated with larger increases in TG. Subsequent significant determinants of changes in $\mathrm{TG}$ were changes in POmax relative to body mass, and changes in $\mathrm{VO}_{2}$ peak, showing a negative relationship with changes in TG. Finally, gender was also included in the regression equation of $\mathrm{TG}$, with on average larger improvements of $\mathrm{TG}$ in men. Age was the only significant determinant of changes in ApoA1, showing on average larger improvements in older subjects. As a consequence, age was the second important determinant of changes in ApoA1/ApoB.

\section{Discussion}

\section{Changes in lipid and (apo) lipoprotein profiles}

Results of the present study show that the lipid and (apo)lipoprotein profiles improve in persons with SCI during the first 2 years post-injury. With the exception of HDL-C, TG, and HDL-C/ApoA1, all parameters showed more favorable values 2 years post-injury. Although HDL-C showed no significant improvement at t2, the $P$-value $(P=0.062)$ was just above the level of significance, indicating that there was at least a tendency for an increase of HDL-C. Moreover, the ratio $\mathrm{TC} / \mathrm{HDL}-\mathrm{C}$, being considered as a stronger predictor of $\mathrm{CHD}$ than $\mathrm{HDL}-\mathrm{C},{ }^{19}$ showed a pronounced decrease from 5.7 at $\mathrm{t} 1$ to 4.9 at $\mathrm{t} 2$. Also ApoA1, the apolipoprotein which is associated with HDL-C, showed a significant increase at $\mathrm{t} 2$ (Table 4).

The low initial values for HDL-C $\left(0.94 \mathrm{mmol}^{-1}\right.$ for men only $[n=15])$ are in agreement with previous

Table 4 Lipid and (apo)lipoprotein profiles at t1 and t2 $(n=19)$

\begin{tabular}{|c|c|c|c|c|}
\hline & $\begin{array}{c}t 1 \\
\text { mean } \pm S D\end{array}$ & $\begin{array}{c}t 2 \\
\text { mean } \pm S D\end{array}$ & $\begin{array}{c}\Delta \\
m e a n \pm S D\end{array}$ & $\mathrm{P}$ value \\
\hline $\mathrm{TC}\left(\mathrm{mmol} . \mathrm{l}^{-1}\right)$ & $5.1 \pm 1.1$ & $4.8 \pm 1.0$ & $-0.27 \pm 0.46$ & 0.021 \\
\hline HDL-C (mmol.1 $\left.{ }^{-1}\right)$ & $0.93 \pm 0.20$ & $1.02 \pm 0.26$ & $0.09 \pm 0.20$ & 0.062 \\
\hline LDL-C $\left(\mathrm{mmol}^{-1}\right)^{\prime}$ & $3.6 \pm 1.0$ & $3.2 \pm 0.8$ & $-0.39 \pm 0.49$ & 0.003 \\
\hline TC/HDL-C & $5.7 \pm 1.7$ & $4.9 \pm 1.5$ & $-0.73 \pm 1.06$ & 0.007 \\
\hline LDL-C/HDL-C & $4.0 \pm 1.6$ & $3.3 \pm 1.1$ & $-0.74 \pm 1.01$ & 0.005 \\
\hline $\mathrm{TG}\left(\mathrm{mmol} .1^{-1}\right)$ & $1.26 \pm 0.31$ & $1.35 \pm 0.62$ & $0.09 \pm 0.54$ & 0.483 \\
\hline ApoA1 $\left(\mathrm{g} .1^{-1}\right)$ & $1.12 \pm 0.14$ & $1.20 \pm 0.21$ & $0.09 \pm 0.16$ & 0.031 \\
\hline $\operatorname{ApoB}\left(\mathrm{g} .1^{-1}\right)$ & $1.11 \pm 0.28$ & $1.05 \pm 0.29$ & $-0.06 \pm 0.12$ & 0.036 \\
\hline ApoA1/ApoB & $1.07 \pm 0.32$ & $1.22 \pm 0.33$ & $0.15 \pm 0.23$ & 0.012 \\
\hline HDL-C/ApoA1 & $0.32 \pm 0.04$ & $0.33 \pm 0.05$ & $0.01 \pm 0.04$ & 0.442 \\
\hline
\end{tabular}

$\mathrm{t} 1$ : during rehabilitation; $\mathrm{t} 2: \pm 1$ year after discharge from rehabilitation; $\Delta$ : value at $\mathrm{t} 2$ minus value at $\mathrm{t} 1$ 
Table 5 Results of multiple regression analyses $(n=19)$

\begin{tabular}{|c|c|c|c|c|}
\hline $\begin{array}{l}\text { Dependent } \\
\text { variables }\end{array}$ & $\begin{array}{c}\text { Regression } \\
\text { coefficients }+ \text { intercepts }\end{array}$ & $\begin{array}{l}\text { Independent } \\
\text { variables }\end{array}$ & P-value & $r^{2}$ \\
\hline$\Delta \mathrm{TC}\left(\mathrm{mmol}^{-1} \mathrm{l}^{-1}\right)$ & $\begin{array}{c}-0.35 \\
0.004 \\
0.35\end{array}$ & $\begin{array}{l}\text { Sport activity } \\
\% \Delta \text { Fiso }\end{array}$ & $\begin{array}{l}0.008 \\
0.013 \\
0.082\end{array}$ & $\begin{array}{l}0.34 \\
0.56\end{array}$ \\
\hline$\Delta \mathrm{HDL}-\mathrm{C}\left(\mathrm{mmol} .1^{-1}\right)$ & $\begin{array}{l}0.002 \\
0.034\end{array}$ & $\% \Delta$ Fiso & $\begin{array}{l}0.019 \\
0.457\end{array}$ & 0.28 \\
\hline$\Delta$ LDL-C $\left(m m o l .1^{-1}\right)$ & $\begin{array}{r}-0.28 \\
-0.21 \\
0.97\end{array}$ & $\begin{array}{l}\text { Sport activity } \\
\text { LDL-C at } \mathrm{t} 1\end{array}$ & $\begin{array}{l}0.003 \\
0.012 \\
0.003\end{array}$ & $\begin{array}{l}0.47 \\
0.65\end{array}$ \\
\hline$\Delta \mathrm{TC} / \mathrm{HDL}-\mathrm{C}$ & $\begin{array}{r}-0.49 \\
-0.26 \\
1.78\end{array}$ & $\begin{array}{l}\text { Sport activity } \\
\text { TC/HDL-C at } t 1\end{array}$ & $\begin{array}{l}0.035 \\
0.040 \\
0.027\end{array}$ & $\begin{array}{l}0.29 \\
0.46\end{array}$ \\
\hline$\Delta \mathrm{LDL}-\mathrm{C} / \mathrm{HDL}-\mathrm{C}$ & $\begin{array}{r}-0.56 \\
-0.03 \\
1.43\end{array}$ & $\begin{array}{l}\mathrm{LDL}-\mathrm{C} / \mathrm{HDL}-\mathrm{C} \text { at } \mathrm{t} 1 \\
\% \mathrm{VO}_{2} \text { peak } / \mathrm{kg}\end{array}$ & $\begin{array}{l}0.000 \\
0.016 \\
0.004\end{array}$ & $\begin{array}{l}0.49 \\
0.65\end{array}$ \\
\hline$\Delta \mathrm{TG}\left(\mathrm{mmol} .1^{-1}\right)$ & $\begin{aligned} & 0.035 \\
- & 0.005 \\
& 0.70 \\
- & 0.012 \\
- & 0.33\end{aligned}$ & $\begin{array}{l}\Delta \text { Sum of skinfolds } \\
\% \Delta \mathrm{POmax} / \mathrm{kg} \\
\text { gender } \\
\% \Delta \mathrm{VO}_{2} \text { peak }\end{array}$ & $\begin{array}{l}0.001 \\
0.013 \\
0.003 \\
0.016 \\
0.065\end{array}$ & $\begin{array}{l}0.22 \\
0.47 \\
0.62 \\
0.75\end{array}$ \\
\hline$\Delta \mathrm{ApoA} 1\left(\mathrm{~g} .1^{-1}\right)$ & $\begin{array}{r}0.006 \\
-0.136\end{array}$ & Age & $\begin{array}{l}0.030 \\
0.191\end{array}$ & 0.25 \\
\hline$\Delta \mathrm{ApoB}\left(\mathrm{g} .1^{-1}\right)$ & $\begin{array}{l}-0.002 \\
-0.004\end{array}$ & $\% \Delta \mathrm{P} 30$ & $\begin{array}{l}0.006 \\
0.892\end{array}$ & 0.37 \\
\hline$\Delta \mathrm{ApoA} 1 / \mathrm{ApoB}$ & $\begin{array}{r}0.003 \\
0.006 \\
-0.208\end{array}$ & $\begin{array}{l}\% \Delta \mathrm{P} 30 \\
\text { Age }\end{array}$ & $\begin{array}{l}0.013 \\
0.047 \\
0.136\end{array}$ & $\begin{array}{l}0.27 \\
0.43\end{array}$ \\
\hline$\Delta$ HDL-C/ApoA 1 & - & - & $\mathrm{ns}$ & - \\
\hline
\end{tabular}

ns: not significant; $\Delta$ : value at $\mathrm{t} 2$ minus value at $\mathrm{t} 1$

results in recently injured individuals. ${ }^{4,17}$ Brenes et $a l^{4}$ found even lower values for HDL-C $\left(0.79 \mathrm{mmol} . \mathrm{l}^{-1}\right)$ in subjects less than 6 weeks post-injury. The increase in HDL-C in the present study is in accordance with the positive cross-sectional relationship between HDL$\mathrm{C}$ levels and time since injury as reported by Brenes et $a l .{ }^{4}$ These findings and the current results suggest that time since injury is an important factor explaining differences in risk profiles during the first 1 or 2 years post-injury, and should therefore be taken into account when investigating lipid and (apo)lipoprotein profiles in persons with SCI.

Despite the improvements found during the first 2 years post-injury, several subjects still demonstrated unfavorable risk profiles at $\mathrm{t} 2$; seven out of 19 subjects showed HDL-C concentrations lower than $0.90 \mathrm{mmol} . \mathrm{I}^{-1}$, indicating that these subjects have an increased risk of CHD. ${ }^{20}$ On the contrary, ApoB levels were lower than previously reported in persons with longstanding SCI. ${ }^{10}$ To determine whether the lipid and (apo)lipoprotein profiles continue to improve, or will decrease after a longer period of time, longitudinal studies in persons with SCI at a longer time scale are required.

Previous cross-sectional results indicate that the largest improvements of the risk profiles do occur shortly after injury. ${ }^{4}$ Improvements of the risk profiles in the present study might therefore be underestimated by differences in time since injury between subjects at t1; some subjects were tested shortly after injury, whereas others were tested at the end of the rehabilitation period. Moreover, because only two measurements were performed in the present study, it remains unclear when the largest improvements did occur.

\section{Determinants of changes in lipid and (apo)lipoprotein profiles}

Results of the regression analyses showed that sport activity and/or improvements of physical capacity parameters were significantly associated with favorable changes of the lipid and (apo)lipoprotein profiles, also when other possible confounding factors were taken into account. Persons with SCI who participated in sports activities and/or revealed larger improvements in physical capacities, showed larger decreases of TC, TC/ HDL-C, LDL-C, LDL-C/HDL-C, TG and ApoB, and (a tendency for) larger increases of HDL-C and ApoA1/ApoB. Results underline the importance of improving the physical capacity during the rehabilitation process. Moreover, the significant associations of sport activity in the year after rehabilitation, with decreases of TC, TC/HDL-C and LDL-C, show that being physically active after rehabilitation results in more favorable risk profiles at 2 years post-injury. 
Hence, an increased risk of CHD as a consequence of unfavorable risk profiles can be reduced by improving the physical capacity and by being active in sport activities.

The results of the present study support previous cross-sectional findings in persons with SCI, showing more favorable lipid and lipoprotein profiles in active persons, in comparison with sedentary persons., ${ }^{4,5}$ The findings are also in agreement with cross-sectional results of Bostom et $a l^{15}$ who found significant relationships between risk profile parameters and aerobic power. However, Bostom et $a l^{15}$ investigated a very homogeneous group of (well-trained) persons with paraplegia. In general, the cross-sectional relationship between physical capacity parameters (used as a measure of training status) and lipid and (apo)lipoprotein profile parameters are confounded by differences in active muscle mass, as a result of differences in lesion level. The large variability in physical capacity for persons with SCI in crosssectional studies, will therefore mainly reflect differences in lesion level, rather than differences in training status. This may also explain the lack of relationship between physical capacity parameters and risk profile parameters in the cross-sectional study of Janssen et al. ${ }^{10}$ In the present longitudinal study, percentage changes in physical capacity were associated with changes in risk profile parameters, resulting in significant relationships.

Previous observations suggested that an increased proportion of adipose tissue in persons with SCI might be in part responsible for the unfavorable lipid and (apo)lipoprotein profiles. ${ }^{8,21}$ The present study, on the contrary, showed more favorable lipid and (apo)lipoprotein values, despite the significant increase of body mass and BMI between $\mathrm{t} 1$ and $\mathrm{t} 2$. However, the lack of change in the sum of four skinfolds suggests that the change in body mass was the consequence of an increased muscle mass, instead of an increase in adipose tissue.

The positive relationship between changes in TC and $\% \Delta$ Fiso, when sport activity was taken into account, was not as expected because an increased muscle force might be the effect of training and is therefore expected to result in a decrease of TC. However, the significant inverse relationship between sport activity and changes in TC showed that being physically active may result in a decrease of TC.

TG was the only parameter showing a tendency for a less favorable concentration at $\mathrm{t} 2$. The significant positive relationship between increases in $\mathrm{TG}$ and increases in the sum of four skinfolds is in agreement with previous cross-sectional observations in persons with long-standing SCI, ${ }^{10}$ and shows the negative effect of an increase of adipose tissue on the CHD risk profiles.

Initial values of LDL-C, TC/HDL-C and LDL-C/ HDL-C showed significant association with changes in the values of these parameters. This is in agreement with previous studies in able bodied subjects, showing that subjects with initially unhealthy levels are more likely to benefit from physical training than persons with better initial lipid and (apo)lipoprotein levels. ${ }^{22}$ From this point of view, the large improvements found in the present study might in part be due to the unfavorable values shortly after injury.

For most changes in the risk profiles sport activity and/or changes in physical capacity were the most important determinants. Only for ApoA1, age was the only significant determinant, showing larger increases with a higher age. Initial values of ApoA1 did not show lower values in older subjects and could therefore not explain the larger increases. At this time, no valid explanation is available for the larger increases of ApoA1 in older subjects.

Although considerable differences exist in the lipid and (apo)lipoprotein profiles between men and women, ${ }^{1,12,23}$ changes in risk profiles were the same when women $(n=4)$ were excluded from the analysis, except for TG, where larger changes were found in men (Table 5). Generally, higher values of HDL-C and ApoA1, and lower values of $A p o B$ are found in women, compared to men. ${ }^{11,12,23}$ However, exclusion of female subjects revealed similar changes for HDL-C (0.94 mmol. $\mathrm{I}^{-1}$ at $\mathrm{t} 1,1.02 \mathrm{mmol} . \mathrm{1}^{-1}$ at $\left.\mathrm{t} 2\right)$, ApoA1 $\left(1.13 \mathrm{~g} .1^{-1}\right.$ at $\mathrm{t} 1,1.22 \mathrm{~g} .1^{-1}$ at $\left.\mathrm{t} 2\right)$, and ApoB (1.13 g. $1^{-1}$ at t1, $1.05 \mathrm{~g} .1^{-1}$ at t2).

\section{Conclusions}

It is concluded that the lipid and (apo)lipoprotein profiles improve in persons with SCI during the first 2 years post-injury. Sport activity and improvements of the physical capacity were associated with more favorable lipid and (apo)lipoprotein profiles, showing that improving the physical capacity by being active in sport activities can improve the CHD risk profiles in persons with a recent SCI.

\section{Acknowledgements}

Support for this project was provided by the Rehabilitation Center Amsterdam, The Netherlands. The authors gratefully acknowledge AM Assen-Wiegers and MC Molema from the clinical laboratory of the Rehabilitation Center Amsterdam for collecting the blood samples.

\section{References}

1 Yekutiel $\mathrm{M}$ et al. The prevalence of hypertension, ischaemic heart diseases and diabetes in traumatic spinal cord injured patients and amputees. Paraplegia 1989; 27: 58-62.

2 Whiteneck GG et al. Mortality, morbidity, and psychosocial outcomes of persons spinal cord injured more than 20 years ago. Paraplegia 1992; 30: 617-630.

3 DeVivo MJ, Black KJ, Stover SL. Causes of death during the first 12 years after spinal cord injury. Arch Phys Med Rehabil 1993; 74: $248-254$.

4. Brenes $\mathrm{G}$ et al. High density lipoprotein cholesterol concentrations in physically active and sedentary spinal cord injured patients. Arch Phys Med Rehabil 1986; 67: 445-450. 
5 Dearwater SR et al. Activity in the spinal cord injured patient: an epidemiologic analysis of metabolic parameters. Med Sci Sports Exerc 1986; 18: $541-544$

$6 \mathrm{Krum} \mathrm{H}$ et al. Risk factors for cardiovascular disease in chronic spinal cord injury patients. Paraplegia 1992; 30: 381-388.

7 Bauman WA, Spungen AM. Disorders of carbohydrate and lipid metabolism in veterans with paraplegia or quadriplegia: A model of premature aging. Metabolism 1994; 43: $749-756$.

8 Maki KC et al. Associations between serum lipids and indicators of adiposity in men with spinal cord injury. Paraplegia 1995; 33: $102-109$.

9 Dallmeijer AJ, Hopman MTE, Woude LHV van der. Lipid, lipoprotein and apolipoprotein profiles in active and sedentary men with tetraplegia. Arch Phys Med Rehabil 1997; 73: $1173-$ 1176.

10 Janssen TW et al. Coronary heart disease risk indicators, aerobic power, and physical activity in men with spinal cord injuries. Arch Phys Med Rehabil 1997; 78: 697-705.

11 Contois JH et al. Reference intervals for plasma apolipoprotein A-1 determined with a standardized commercial immunoturbidimetric assay: results from the Framingham Offspring Study. Clin Chem 1996; 42: $507-514$.

12 Contois $\mathrm{JH}$ et al. Reference intervals for plasma apolipoprotein B determined with a standardized commercial immunoturbidimetric assay: results from the Framingham Offspring Study. Clin Chem 1996; 42: 515-523.

13 Hjeltnes N, Vokac Z. Circulatory strain in everyday life of paraplegics. Scand J Rehabil Med 1979; 11: 67-73.

14 Janssen TWJ, van Oers CAJM, van der Woude LHV, Hollander AP. Physical strain in daily life of wheelchair users with spinal cord injuries. Med Sci Sports Exerc 1994; 26: 661-670.
15 Bostom AG et al. Lipid and lipoprotein profiles relate to peak aerobic power in spinal cord injured men. Med Sci Sports Exerc 1991; 23: 409-414.

16 Hooker SP, Wells CL. Effect of low- and moderate-intensity training in spinal cord-injured persons. Med Sci Sports Exerc 1989; 21: $18-22$.

17 Walker J, Shephard RJ. Cardiac risk factors immediately following spinal injury. Arch Phys Med Rehabil 1993; 74: $1129-1133$.

18 Dallmeijer AJ, van der Woude LHV, Hollander AP, van As HHJ. Physical capacity and performance of activities of daily living during rehabilitation in persons with spinal cord injuries. Med Sci Sports Exerc, in press.

19 Stampfer MJ et al. A prospective study of cholesterol, apolipoproteins, and the risk of myocardial infarction. $N$ Engl J Med 1991; 325: 373 - 381.

20 Gordon DJ et al. High-density lipoprotein cholesterol and cardiovascular disease: four prospective American studies. Circulation 1989; 79: 8-15.

21 Kocina P. Body composition of spinal cord injured adults. Sports Med 1997; 23: 48 - 60 .

22 Tran ZV, Weltman A, Glass GV, Mood DP. The effects of exercise on blood lipids and lipoproteins: a meta-analysis of studies. Med Sci Sports Exerc 1983; 15: 393-402.

23 Johnson CL et al. Declining serum total cholesterol levels among US adults. The national health and nutrition examination surveys. JAMA 1993; 269: $3002-3008$. 